\title{
SISTEM INFORMASI GEOGRAFIS \\ PEMETAAN SUARA PEMILUKADA BERBASIS OPEN SOURCE DI KABUPATEN JOMBANG
}

\author{
M. Kirom \\ Universitas Pesantren Tinggi Darul 'Ulum \\ Jombang, Indonesia \\ Kiromchoice@gmail.com
}

\begin{abstract}
Abstrak
Pemilihan umum (Pemilu) merupakan kesempatan bagi warga negara untuk memilih pejabatpejabat pemerintah dan memutuskan apakah yang mereka inginkan untuk dikerjakan oleh pemerintah. Hasil pemilihan umum hanya dapat dilihat di Tempat Pemungutan Suara dan data yang diberikan belum dapat memberikan informasi secar maksimal serta pengelolaan beberapa data masih konvensional. Sistem Informasi Geografis (SIG) didefinisikan sebagai alat atau media untuk memasukkan, menyimpan, mengambil, memanipulasi, menganalisa dan menampilkan data-data beratribut geografis (data spasial). SIG dapat menampilkan informasi yang beragam dalam suatu bidang gambar. Salah satu sistem informasi yang dapat dikembangkan untuk memberikan informasi hasil suara pemilihan umum kepala daerah di Kabupaten Jombang adalah dengan menggunakan Sistem Informasi Geografis (SIG) berbasis open source. Sistem ini dibangun dengan mengunakan software SIG yang open source. Sistem ini memiliki fitur menampilkan data Daftar Pemilih Tetap, persentase perolehan suara, persentase golput, jumlah penduduk berdasarkan kelompok umur dan jenis kelamin, mata pencaharian penduduk yang disajikan dalam bentuk grafis (peta). Teknologi SIG berbasis web dalam sistem ini dapat menjadi media informasi yang dapat membantu pihak yang berkepentingan dalam pengambilan keputusan, terutama pihak yang berkaitan dalam proses politik.
\end{abstract}

Kata Kunci: Pemilihan Umum, Web SIG, Open Source, Jombang 


\begin{abstract}
Elections (elections) are an opportunity for citizens to elect government officials and decide whether they want to be done by the government. The results of the general election can only be seen in the polling stations and the data provided cannot provide the maximum of information abundance, as well as some data is still conventional management. Geographic Information System (GIS) is defined as a tool or medium to enter, store, retrieve, manipulate, analyze, and display geographic attribute data (spatial data). GIS can display a variety of information in an image field. One of the information systems can be developed to provide sound information on the results of regional head elections in Jombang is to use a Geographic Information System (GIS) based on open source. The system is built using the open source GIS software. The system features a data showing the voters list, the percentage of the popular vote, the percentage of non-voters, the number of population by age group and gender, livelihoods are presented in graphical form (map). Web-based GIS technology in this system can be a medium of information that can assist interested parties in making decisions, especially those related to the political process
\end{abstract}

Keywords: Election, Web GIS, Open Source, Jombang 


\section{PENDAHULUAN}

Pemiluhan umum (Pemilu) adalah kesempatan bagi warga negara untuk memilih pejabat-pejabat pemerintah dan memutuskan apakah yang mereka inginkan untuk dikerjakan oleh pemerintah (Harris G. Warren). Sedangkan menurut UU No. 3 tahun 1999, Pemilu adalah sarana pelaksanaan kedaulatan rakyat dalam negara kesatuan RI yang berdasarkan pancasila dan UUD 1945.

Selama ini hasil perhitungan pemilihan umum kepala daerah (pemilihan bupati) hanya dapat dilihat pada saat perhitungan suara di Tempat Pemungutan Suara (TPS) atau perhitungan cepat (Quick Count). Ketika proses pemungutan suara telah selesai data hasil pemilu hanya bisa dilihat di kantor Komisi Pemilihan Umum (KPU) dan data yang diberikan belum dapat memberikan informasi secara maksimal, seperti belum adanya informasi mengenai jumlah golput, persentase perolehan suara masing-masing calon dan wakil calon bupati serta pengelolaan beberapa data masih konvensional.

Sistem Informasi Geografis (SIG) didefinisikan sebagai alat atau media untuk memasukkan, menyimpan, mengambil, memanipulasi, menganalisa dan menampilkan data - data beratribut geografis (data spasial) yang berguna untuk mendukung proses pengambilan keputusan dalam perencanaan dan managemen sumber daya alam, lingkungan, transfortasi, masalah perkotaan dan administratif (Indarto, 2010). SIG dapat menampilkan informasi yang beragam dalam suatu bidang gambar.

Salah satu sistem informasi yang dapat dikembangkan untuk memberikan informasi hasil suara pemilihan umum kepala daerah di Kabupaten Jombang adalah dengan menggunakan Sistem Informasi Geografis (SIG) berbasis open source. Informasi yang dihasilkan dalam SIG ini berupa data spasial (peta) yang memberikan informasi jumlah penduduk, mata pencaharian penduduk, Daftar Pemilih Tetap (DPT), persentase suara yang diperoleh masing-masing calon bupati dan wakil calon bupati, persentase golput. Teknologi SIG berbasis web dalam sistem ini diharapkan mampu menjadi media informasi yang dapat membantu pihak yang berkepentingan dalam pengambilan keputusan, terutama pihak yang berkaitan dalam proses politik.

\section{Definisi Sistem Informasi}

Sistem informasi menjadi sebuah bentuk penerapan teknologi informasi dan komunikasi, yang dikembangkan dalam sebuah organisasi. Sistem informasi apabila diperhatikan terdiri dari dua struktur kata yaitu Sistem dan Informasi.

Sistem yaitu suatu kumpulan atau himpunan dari unsur, komponen atau variabel-variabel yang terorganisasi, saling berinteraksi, saling bergantung satu sama lain dan terpadu (Sutabri, 2004). Menurut Winarno sistem adalah sekumpulan komponen yang saling bekerja sama untuk mencapai suatu tujuan, masing-masing komponen memiliki fungsi yang berbeda dengan yang lain, tetapi tetap dapat bekerja sama (Winarno, 2006). Berdasarkan penjelasan tersebut, maka dapat disimpulkan bahwa suatu sistem merupakan sekumpulan komponen, unsur atau variabel yang berjalan secara terpadu dan saling bekerja sama untuk mencapai suatu tujuan. 
Informasi adalah data yang diolah menjadi bentuk yang berguna bagi para pemakainya (Jogiyanto, 2005). Menurut Sutanta, suatu informasi merupakan hasil pengolahan data sehingga menjadi bentuk yang penting bagi penerimana dan mempunyai kegunaan sebagai dasar dalam pengambilan keputusan yang dapat dirasakan akibatnya secara langsung saat itu juga atau secara tidak langsung pada saat mendatang (Sutanta, 2004).

Sistem informasi adalah kumpulan dari sub-sub sistem baik fisik maupun non fisik yang saling berhubungan satu sama lain dan bekerja sama secara harmonis untuk mencapai satu tujuan yaitu mengolah data menjadi informasi yang berguna (Azhar, 2004). Sistem informasi dapat digunakan untuk menghasilkan informasi dengan lebih baik, informasi tersebut digunakan untuk membantu membuat keputusan yang lebih baik.

\section{Sistem Informasi Geografis}

Sistem Informasi Geografis (SIG) atau Geography Information System (GIS) merupakan gabungan dari tiga unsur pokok yaitu sistem, informasi dan geografis. SIG lebih menekankan pada unsur informasi geografis yaitu suatu kesatuan formal yang terdiri dari berbagai sumber daya fisik dan logika yang berkenaan dengan objek-objek yang terdapat di permukaan bumi. SIG dapat juga dikatakan sebagai sejenis perangkat lunak yang dapat digunakan untuk pemasukan, penyimpanan, manipulasi, menampilkan dan keluaran informasi geografis berikut atributatributnya (Bafdal, 2011).

Dapat disimpulkan bahwa SIG adalah sistem informasi berbasis komputer yang dirancang untuk digunakan sebagai tempat penyimpanan, memproses, manipulasi, serta menyajikan data yang bergeoreferensi serta memiliki sistem database tersendiri yang disimpan dalam suatu basis data dan berhubungan dengan keadaan nyata (real world). SIG bersifat dinamik, memiliki kemampuan menyeleksi data, menampilkan suatu informasi dan mampu menyatukan unsur-unsur pada peta sesuai dengan keperluan pengguna.

\section{Data Spasial}

Data spasial adalah suatu data yang mengacu pada posisi, objek serta hubungan antar keduanya dalam rung bumi. Data spasial merupakan salah satu komponen dari informasi, dimana didalamnya terdapat informasi mengenai bumi, sperti permukaan bumi, bawah permukaan bumi, perairan, kelautan serta bawah atmosfir. Data spasial dibagi menjadi dua, yaitu model data raster dan model data vector.

Model data raster mempunyai struktur data yang tersusun dalam bentuk matriks atau piksel dan membentuk grid. Setiap piksel mempunyai nilai tertentu dan atribut tersendiri, termasuk nilai kordinat bumi yang unik. Model data raster merupakan jenis model data spasial paling sederhana.

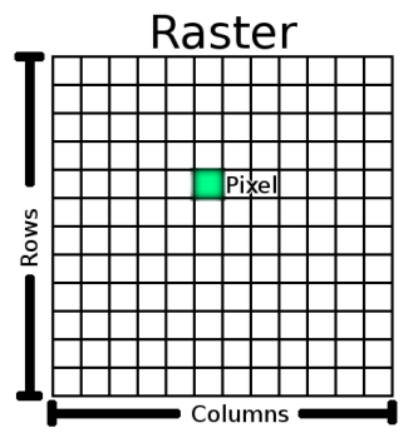

Gambar 1. Model data raster

Model data vector merupakan jenis model data spasial yang berbasiskan pada 
titik (point) dengan menggunakan nilai koordinat $(\mathrm{X}, \mathrm{Y})$ untuk membuat atau membangun objek spasial. Objek yang dibangun terbagi menjadi tiga bagian, yaitu:

1. Titik (point): Titik merupakan representasi grafis paling sederhana pada suatu objek. Titik tidak mempunyai dimensi tetapi dapat ditampilkan dlam peta maupun yang lainnya. contoh: Lokasi peristirahatan, Lokasi wisata dan lain sebagainya.

Gambar 2. Data vector titik (point)

2. Garis (line): Garis merupakan penghubung antara dua titik atau lebih dan mempresentasikan objek dalam satu dimensi. Contoh: Jalan, sungai, batas daerah dan lain sebagainya.

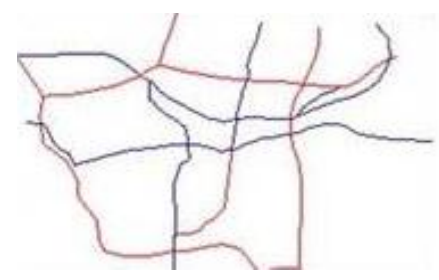

Gambar 3. Data vector garis (line)

3. Area (polygon): Merupakan representasi objek dalam dua dimensi. Contoh : Danau, persawahan dan lain sebagainya.

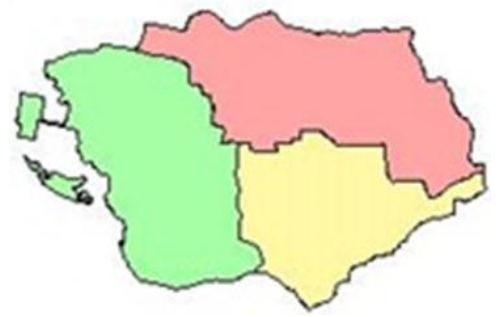

Gambar 4. Data vector area (polygon)

\section{Open Source}

Suatu software dapat dikatakan sebagai open source bila user diperbolehkan dan diberi kemudahan untuk mendapatkan akses ke kode sumber (open source). Suatu produk open source juga harus memnuhi kriteria-kriteria sebagai berikut (Ferdinan, 2008) :

1. Bebas didistribusikan, lisensi software terbuka bagi semua pihak.

2. Program yang didistribusikan harus disertai dengan kode sumber dan harus memungkinkan pendistribusian dalam bentuk kode sumber maupun yang sudah terkompilasi.

Lisensi memungkinkan user untuk memodifikasi software dan membuat produk turunannya. Produk turunan tersebut ketika didistribusikan harus mengikuti syarat-syarat yang ada pada lisensi awal. Produk turunan harus mengenalkan nomor versi atau nama yang berbeda dari software aslinya.

\section{METODE PENELITIAN}

\section{Metode Perancangan Sistem}

Dalam melakukan perancangan sistem penulis menggunakan metode Waterfall. Perancangan Sistem Informasi Geografis Pemetaan Suara Pemilukada menyajikan informasi data spasial tentang hasil pemilukada pada masing-masing daerah di Kabupaten Jombang kepada pengguna. Informasi data spasial direpresentasikan dalam bentuk grafis, sedangkan informasi atribut direpresentasikan dalam bentuk tabel. Berikut merupakan tahapan dalam pembuatan sistem pemetaan suara pemilukada:

1. Mengumpulkan data tentang hasil suara pemilukada. 
2. Menganalisa data dan merancang Sistem Informasi Geografis.

3. Mendigitasi data-data spasial.

4. Membuat tampilan antar muka.

\section{Kebutuhan Data}

1. Data Spasial

Data spasial yang dipakai adalah berupa data peta Kabupaten Jombang dan peta kecamatan yang ada di wilayah Kabupaten Jombang dalam sistem koordinat yang telah diolah sesuai dengan kebutuhan sistem. Berikut gambar peta Kabupaten Jombang dan peta Kecamatan.
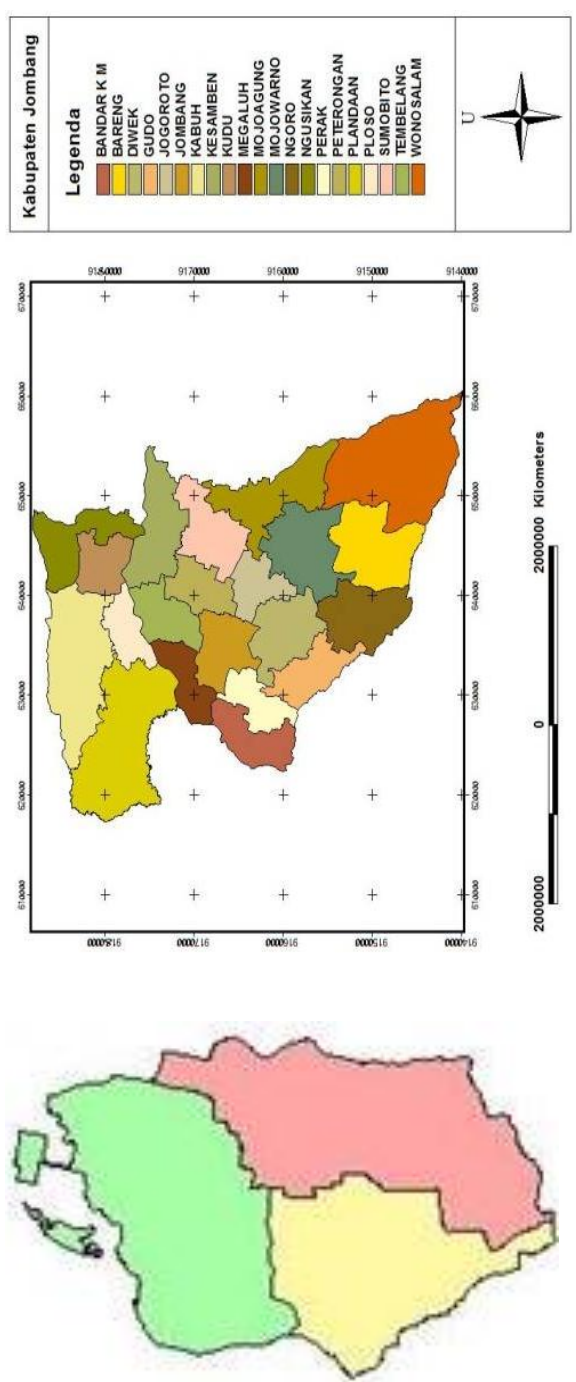

Gambar 5. Peta kabupaten Jombang
2. Data Nonspasial

Data Nonspasial merupakan data atribut yang mendeskripsikan peta atau informasi pada peta. Disini salah satu data nonspasial yang digunakan adalah data Daftar Pemilih Tetap (DPT) dari tiap-tiap desa per kecamatan di Kabupaten Jombang.

Tabel 1. Daftar Pemilih Tetap Kcamatan Diwek

\begin{tabular}{|c|c|c|c|}
\hline $\begin{array}{l}\mathrm{Nm} \\
\text { Desa }\end{array}$ & $\begin{array}{c}\text { Laki- } \\
\text { laki }\end{array}$ & $\begin{array}{c}\text { Perem } \\
\text {-puan }\end{array}$ & $\begin{array}{l}\text { Jml } \\
\text { Dpt }\end{array}$ \\
\hline $\begin{array}{c}\text { Kayan } \\
\text { gan }\end{array}$ & 2369 & 2433 & 4802 \\
\hline Puton & 1220 & 1237 & 2457 \\
\hline Bendet & 997 & 1003 & 2000 \\
\hline $\begin{array}{c}\text { Bulure } \\
\text { jo }\end{array}$ & 2924 & 2852 & 5776 \\
\hline Grogol & 3070 & 2989 & 6059 \\
\hline $\begin{array}{c}\text { Jatirej } \\
\text { o }\end{array}$ & 1960 & 1877 & 3837 \\
\hline Cukir & 2924 & 2964 & 5888 \\
\hline $\begin{array}{c}\text { Kwaro } \\
n\end{array}$ & 2003 & 2047 & 4050 \\
\hline $\begin{array}{c}\text { Watug } \\
\text { aluh }\end{array}$ & 1694 & 1634 & 3328 \\
\hline $\begin{array}{c}\text { Pundo } \\
\text { ng }\end{array}$ & 1823 & 1875 & 3698 \\
\hline Diwek & 1567 & 1675 & 3242 \\
\hline $\begin{array}{c}\text { Bandu } \\
\text { ng }\end{array}$ & 4109 & 3814 & 7923 \\
\hline $\begin{array}{c}\text { Kedaw } \\
\text { ung }\end{array}$ & 1047 & 1051 & 2098 \\
\hline $\begin{array}{l}\text { Ngudir } \\
\text { ejo }\end{array}$ & 1754 & 1765 & 3519 \\
\hline $\begin{array}{c}\text { Cewen } \\
\text { g }\end{array}$ & 1528 & 1679 & 3207 \\
\hline $\begin{array}{c}\text { Balong } \\
\text { besuk }\end{array}$ & 1960 & 2019 & 3979 \\
\hline $\begin{array}{c}\text { Panda } \\
\text { nwang } \\
\text { i }\end{array}$ & 2420 & 2388 & 4808 \\
\hline $\begin{array}{c}\text { Bramb } \\
\text { ang }\end{array}$ & 931 & 929 & 1860 \\
\hline $\begin{array}{c}\text { Jatipel } \\
\text { em }\end{array}$ & 1384 & 1414 & 2798 \\
\hline Keras & 2511 & 2507 & 5018 \\
\hline
\end{tabular}




\section{Desain Perancangan Sistem}

Input dari perancangan sistem informasi geografis ini adalah berupa data spasial (Peta kecamatan yang ada di Kabupaten Jombang) dan data atribut (hasil suara pemilukada, daftar pemilih pada tiap-tiap kecamatan atau desa). Arsitekturnya seperti Gambar 2

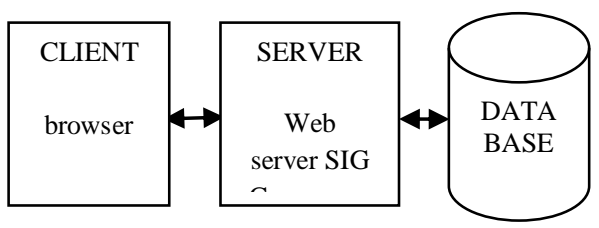

Gambar 6. Arsitektur web SIG

Client menggunakan browser yang ada di perangkat komputer untuk mengakses web, dengan menggunakan protokol browser terhubung ke server, dari server halaman web SIG yang diminta oleh client akan diambil dari database. Web SIG yang ada di database akan dikirim kembali ke server, dari server akan dikirim ke browser client.

1. Konteks Diagram

Konteks diagram merupakan DFD (Data Flow Diagram) yang menggambarkan sebagian besar proses operasional pada sistem.

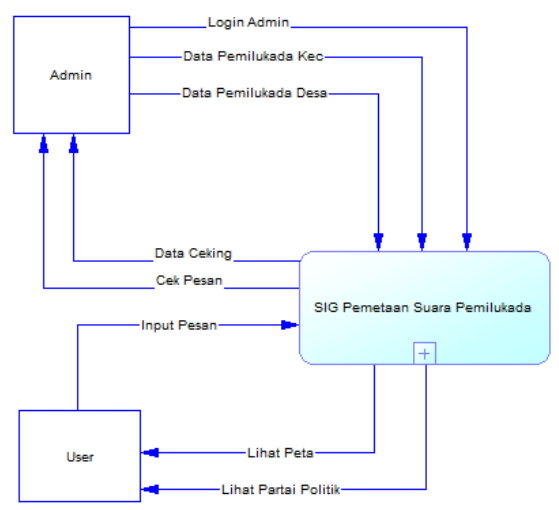

Gambar 7. Konteks diagram SIG pemetaan suara pilkada
Di dalam gambar terlihat bahwa sistem yang dirancang melibatkan dua sumber atau tujuan data sebagai aktor dalam sistem, yaitu admin dan user (pengunjung).

Admin didalam sistem memiliki berbagai tugas, yaitu mengelola data pemilukada desa, data pemilukada kecamatan dan data partai politik, sementara itu user (pengunjung) hanya dapat melakukan input pesan, melihat peta, membaca profil dari Kabupaten Jombang atau profil dari KPUD Jombang.

\section{Perancangan Database}

Pada perancangan database ini memerlukan ERD yang menunjukkan relasi antar entitas. Perancangan ERD ini berdasarkan Conseptual Data Model (CDM) yang menghasilkan Phisical Data Model (PDM). Entity Relationship Diagram (ERD) merupakan salah satu cara untuk mengolah database sehingga data tersebut dapat diketahui hubungan antar file.

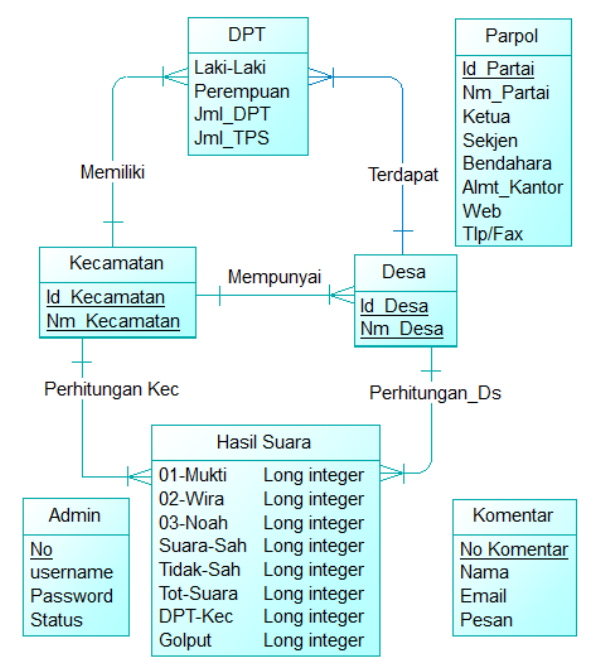

Gambar 8. Conseptual Data Model (CDM)

Dari gambar 3.8 terdapat tabel-tabel yang saling berhubungan yaitu tabel DPT, Kecamatan, Desa dan Hasil Suara. 
Hubangan tabel Kecamatan dengan tabel Desa adalah satu ke banyak (one to many), dimana setiap satu kecamatan memiliki banyak desa dan minimal satu kecamatan memiliki satu desa.

Hubungan tabel Kecamatan dengan tabel DPT adalah satu ke banyak (one to many), setiap kecamatan memiliki banyak DPT dan setiap kecamatan harus memiliki DPT, tidak boleh kosong.

Hubungan tabel Desa dengan tabel Hasil Suara adalah satu ke banyak (one to many), setiap desa memiliki banyak perhitungan hasil suara.

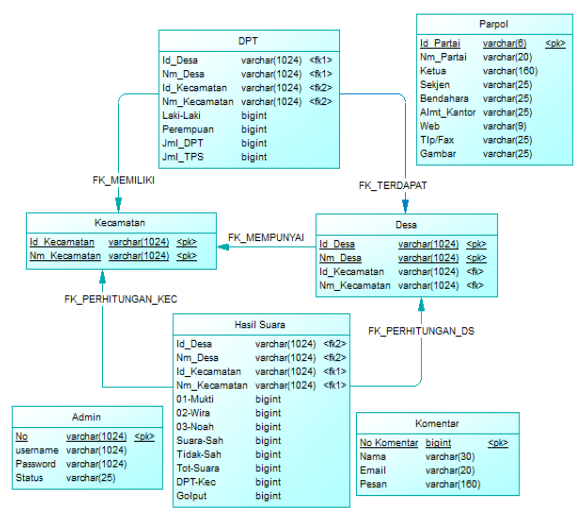

Gambar 9. Phisical Data Model (PDM)

\section{HASIL PENELITIAN DAN}

\section{PEMBAHASAN}

\section{Halaman Beranda}

Tampilan awal ketika user pertama kali membuka aplikasi akan masuk ke halaman beranda. Halaman ini memberikan informasi mengenai aplikasi.

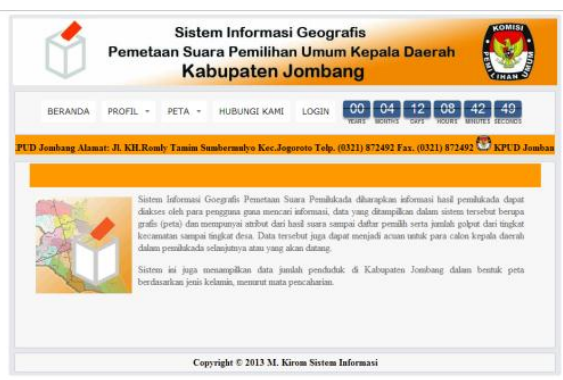

\section{Halaman Profil Jombang}

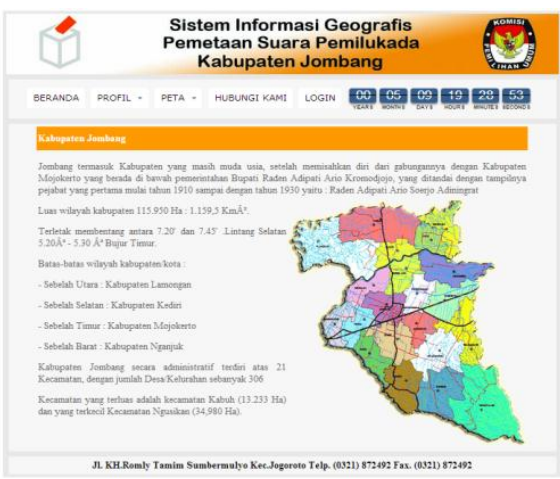

Gambar 11. Halaman profil Jombang

Halaman profil Jombang menampilkan mengenai profil geografis dari wilayah Kabupaten Jombang. Memberikan informasi mengenai batasbatas wilayah kabupaten serta luas wilayah kabupaten, seperti yang terlihat pada gambar 11

\section{Halaman Peta di Tingkat Desa}

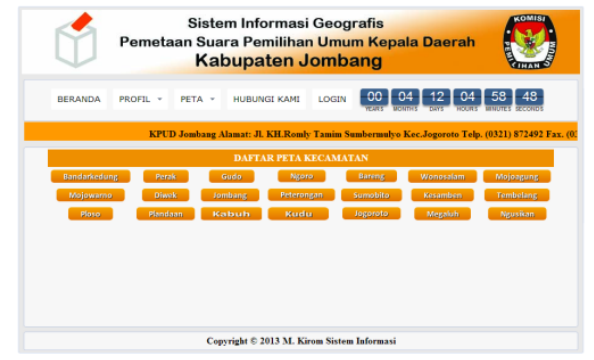

Gambar 12. Daftar pilihan peta kecamatan di Kabupaten Jombang

Halaman ini menampilkan mengenai pemilihan umum kepala daerah di tiap-tiap desa, dengan memberikan pilihan daftar kecamatan yang nantinya apabilah user memilih salah satu daftar nama-nama kecamatan maka akan ditampilkan peta kecamatan yang telah dipilih oleh user dan informasi mengenai pilkada pada desadesa yang ada pada kecamatan tersebut. 


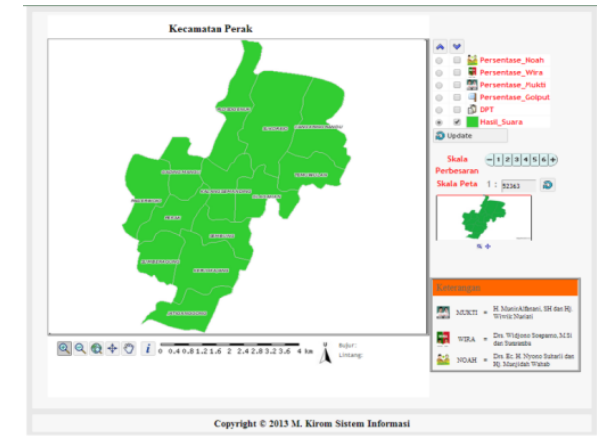

Gambar 13. Peta Kecamatan Perak

Pada gambar 13 adalah contoh peta Kecamatan Perak.

\section{Layer Persentase Suara Pemilukada}

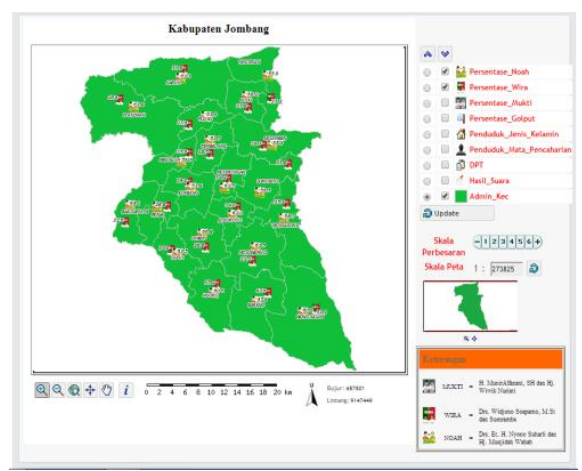

Gambar 14. Persentase perolehan suara pemilukada

Pada gambar 13 menampilkan perolehan persentase suara pasangan Drs. EC. H. Nyono Suharli dengan $\mathrm{Hj}$. Munjidah Wahab (Noah) dan pasangan Drs. Widjono Soeparno, M.Si dengan Sumramba (Wira). Hampir diseluruh wilayah Kabupaten Jombang pasangan Noah memperoleh suara lebih dari 50\%. Hanya pada Kecamatan Bareng pasangan Noah memperoleh persentase yang sama dengan pasangan Wira yaitu $47,91 \%$. Perolehan suara tersebut juga dapat dipengaruhi oleh selisih jumlah DPT dan jumlah pendududuk antara laki-laki dengan perempuan.

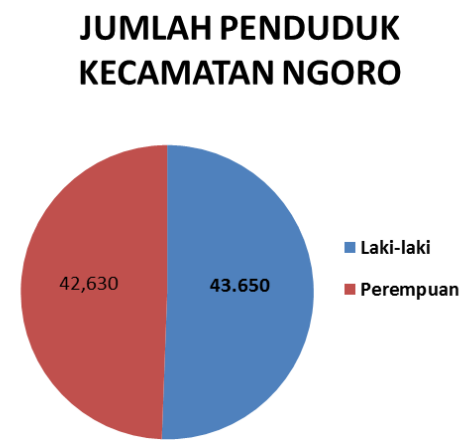

Gambar 15. Jumlah penduduk Kecamatan Ngoro

Pada gambar 15 dan gambar 16 terlihat selisih perbandingan jumlah penduduk antara laki-laki dengan perempuan di Kecamatan Ngoro dan Kecamatan Bareng. Data tersebut dapat mempengaruhi selisih perolehan suara antar pasangan bupati dan wakil bupati, dimana pasangan Noah di Kecamatan Bareng memperoleh suara $47,91 \%$ begitu juga pasangan Wira memperoleh suara yang sama. Sedangkan di Kecamatan Ngoro pasangan Noah memperoleh suara $60,6 \%$, pasangan Wira memperoleh suara $35,2 \%$.

\section{JUMLAH PENDUDUK KECAMATAN BARENG}
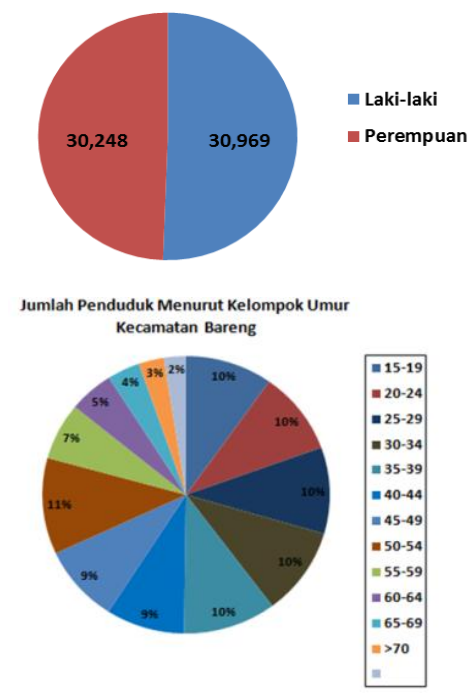

Gambar 16. Jumlah penduduk Kecamatan Bareng 


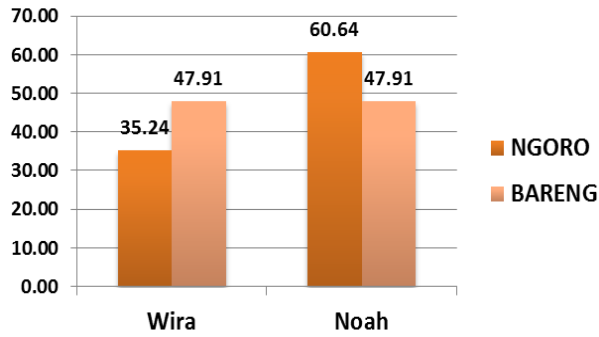

Gambar 17. Persentase perolehan suara antara Noah dan Wira

Pada gambar 18 menunjukkan jumlah penduduk berdasarkan umur di Kecamatan Ngoro dan Gambar 19 menunjukkan jumlah penduduk berdasarkan umur di Kecamatan Barang. Data-data tersebut dapat digunakan sebagai bahan untuk strategi kampaye. Data-data tersebut juga dapat menjadi salah satu faktor kemenangan dari calon bupati dan calon wakil bupati.

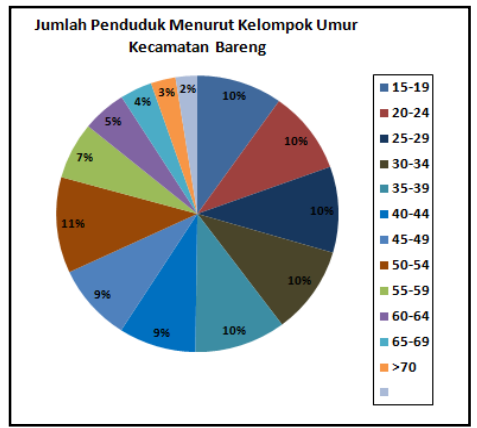

Gambar 20. Persentase jumlah penduduk menurut kelompok umur di Kecamatan Bareng

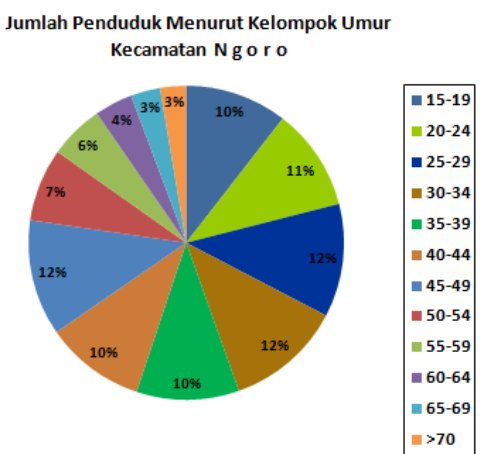

Gambar 21. Persentase jumlah penduduk menurut kelompok umur di Kecamatan

Ngoro

\section{KESIMPULAN DAN SARAN \\ Kesimpulan}

Setelah melakukan perancangan dan pembuatan Sistem Informasi Geografis Pemetaan Suara Pemilihan Umum Kepala Daerah Kabupaten Jombang Berbasis Open Source GIS, maka dapat diambil kesimpulan,

1. Aplikasi tersebut dibangun menggunakan MapWindow sebagai software digitasi peta yang merupakan aplikasi GIS open sourse.

2. Applikasi tersebut diharapkan mampu menjadi media informasi yang memberikan informasi kepada pihak dalam pengambilan keputusan, terutama pihak yang berkaitan dalam proses politik.

\section{Saran}

Beberapa saran yang dapat diajukan dalama pengembangan sistem ini adalah:

1. Pengembang sistem dapat melakukan perubahan data atau atribut dalam peta secara langsung dari web tanpa harus melakukan input manual (digitasi) terlebih dahulu.

2. Komputer yang digunakan untuk mengakses web memiliki layar minimal 
12"(inch) atau resolusi yang tinggi agar tampilan web dapat maksimal. Terutama terhadap tampilan detail peta dan angka (atribut).

3. Pada pengembangan sistem selanjutnya, sistem dapat dikembangkan dalam basis mobile, sehingga lebih mudah dalam pengaksesan. Mengingat saat ini akses internet secara mobile mengalamai kenaikan secara signifikan.

\section{DAFTAR PUSTAKA}

Azhar, Susanto. 2004. Sistem Informasi Manajemen. Bandung: Linggar Jaya.

Bafdal, N. 2011. Buku Ajar Sistem Informasi Geografis. Bandung: Jurusan Teknik Manajemen Industri Pertanian Fakultas Teknologi Industri Pertanian Unpad. Diunduh dari http://pustaka.unpad.ac.id/wpcontent/ uploads/2012/02/pustaka_unpad_buk u_ajar_sistem_informasi_geografis.p df. Pada tanggal 30 November 2013 pukul 12.05 WIB.

Ferdinan, U,. Indarto,. Arif. 2008. Teori dan Aplikasi Open Source GIS menggunakan MapWindow. Yogyakarta: Andi Publisher.

Jogiyanto, H. 2005. Analisis dan Desain Sistem Informasi Pendekatan Terstruktur. Yogyakarta: Andi Publisher.

Sutabri, T. 2004. Analisa Sistem Informasi. Yogyakarta: Andi Publisher.
Sutanta, E. 2004. Sistem Informasi Manajemen. Yogyakarta: Graha Ilmu.

Winarno, Sugeng. 2006. Jaringan Komputer dengan TCP/IP. Bandung: Penerbit Informatika. 
